\title{
Comparative Validation Study to Assay Milnacipran Hydrochloride in Capsules by a Stability-Indicating LC and a Second Order Derivative UV Spectroscopic Methods
}

\section{Carolina Lupi Dias*, Lisiane Bajerski, Rochele Cassanta Rossi, Ana Maria Bergold and Pedro Eduardo Fröehlich}

Graduate Program in Pharmaceutical Sciences, College of Pharmacy, Federal University of Rio Grande do Sul (UFRGS). Avenida Ipiranga, 2752/704, Porto Alegre / RS CEP 90610-000, Brazil

\begin{abstract}
A selective stability-indicating LC method and a second order derivative UV spectroscopic method (UV-D²) were developed to assay milnacipran in pharmaceutical formulation. The LC method was developed with a Nucleosil C8 analytical column and a mobile phase consisting of acetonitrile, water and triethylamine (at $210 \mathrm{~nm}$ ). The validation of UV-D ${ }^{2}$ (zero-crossing method) was based on recording the second-derivative spectra for milnacipran hydrochloride at $268.5 \mathrm{~nm}$ of its solutions in $0.1 \mathrm{~N} \mathrm{HCl}$ and the parameters specificity, linearity, precision, and accuracy were evaluated to both methods. The linear dynamic range was $20-100 \mu \mathrm{g}-\mathrm{mL}^{-1}\left(\mathrm{R}^{2} \geq 0.999\right)$. The validation data showed that both methods are reproducible, providing an accurate (98.5\% to $101.6 \%)$ and precise (RSD $\leq 1.0 \%$ ) quantitation of milnacipran in capsules. The methods proposed showed satisfactory results and were statistically equivalent.
\end{abstract}

Keywords: Milnacipran capsules; Stability-indicating liquid chromatography; Derivative UV spectroscopy; Validation; Quality control

\section{Introduction}

Milnacipran is an antidepressant drug and it is available in some European Countries and in Japan for the treatment of depression. Recently, it was approved by the Food and Drug Administration (FDA) for the management of fibromyalgia syndrome, characterized by widespread pain and decreased physical function.

Milnacipran hydrochloride (Figure 1) is a racemic mixture of $\quad( \pm$ )-[1RS,2SR]-2-(aminomethyl)-N,N-diethyl-1phenylcyclopropanecarboxamide hydrochloride; CAS 101152-947; mol. formula $\mathrm{C}_{15} \mathrm{H}_{22} \mathrm{~N}_{2} \mathrm{O} \cdot \mathrm{HCl}$; mol. wt. 282.81 [1,2]. This agent is unique among clinically available dual-reuptake inhibitors antidepressants in its preferential blockade of norepinephrine (NE) reuptake over serotonin (SER) reuptake and minimal activity at other receptors or transporters. This profile is in contrast to those of SER$\mathrm{NE}$ reuptake inhibitors (SNRI) (e.g., venlafaxine and duloxetine), where SER reuptake is preferentially blocked, or NE-specific agents (noradrenergic reuptake inhibitors [NARIs]) (e.g., reboxetine) in which the reuptake of NE is blocked almost exclusively [3,4].

Some liquid chromatographic (LC) methods for determination of milnacipran combined with other antidepressants in human plasma have already been published [5-9]. A micellar electrokinetic capillary chromatographic method was developed for separation and determination of antidepressants and their metabolites in biological fluids [10] and LC enantioseparation of milnacipran was investigated on different cellulose-based chiral stationary phases [11]. However, there is no reference for $\mathrm{LC}$ determination of milnacipran hydrochloride in pharmaceutical dosage form. The purpose of

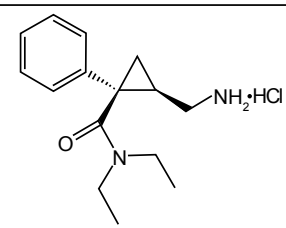

Figure 1: Chemical structure of milnacipran hydrochloride. this study was to develop and validate a simple and fast stabilityindicating LC method according to guidelines [12-14], which require the forced degradation of the active substance under several stress conditions, besides an alternative spectroscopic method, equivalent to the LC method for the quality control of milnacipran in capsules.

\section{Material and Methods}

\section{Chemicals}

Milnacipran hydrochloride was purchased from Synfine Research (Canada). Milnacipran hydrochloride capsules $(25 \mathrm{mg})$ were commercially available and claimed to contain $21,77 \mathrm{mg}$ as milnacipran base and the following inactive ingredients: dibasic calcium phosphate, povidone, carboxymethylcellulose calcium, colloidal silicon dioxide, magnesium stearate and talc (Pierre Fabre Médicament, Boulogne, França). All chemicals used were of analytical grade and all solvents were of LC grade. Methanol and acetonitrile were from J.T. Baker (Phillipsburg, NJ, USA). Hydrochloric acid, sodium hydroxide and 30\% hydrogen peroxide were from Nuclear (CAQ-Diadema, SP, Brazil). Phosphoric acid was from Merck (Darmstadt, Germany). Ethanol was from Vetec (Rio de Janeiro, RJ, Brazil). Ultrapure water (Milli-Q Plus, Millipore ${ }^{\circledR}$, Milford, MA, USA) was used throughout the analysis.

\section{Chromatographic conditions}

The LC system consisted of a Shimadzu (Kyoto, Japan) LC-10AD

*Corresponding author: Carolina Lupi Dias, Graduate Program in Pharmaceutical Sciences, College of Pharmacy, Federal University of Rio Grande do Sul (UFRGS), Avenida Ipiranga, 2752/704, Porto Alegre / RS CEP 90610-000, Brazil, E-mail: carolina.lupi@ufrgs.br

Received August 30, 2010; Accepted September 27, 2010 Published September 30,2010

Citation: Dias CL, Bajerski L, Rossi RC, Bergold AM, Fröehlich PE (2010) Comparative Validation Study to Assay Milnacipran Hydrochloride in Capsules by a Stability-Indicating LC and a Second Order Derivative UV Spectroscopic Methods. Pharm Anal Acta 1:112. doi:10.4172/2153-2435.1000112

Copyright: () 2010 Dias CL, et al. This is an open-access article distributed under the terms of the Creative Commons Attribution License, which permits unrestricted use, distribution, and reproduction in any medium, provided the original author and source are credited. 
Citation: Dias CL, Bajerski L, Rossi RC, Bergold AM, Fröehlich PE (2010) Comparative Validation Study to Assay Milnacipran Hydrochloride in Capsules by a Stability-Indicating LC and a Second Order Derivative UV Spectroscopic Methods. Pharm Anal Acta 1:112. doi:10.4172/21532435.1000112

Page 2 of 5

liquid chromatograph, SPD-M10A $\mathrm{VP}_{\mathrm{VP}}$ diode array detector, Rheodyne ${ }^{\circledR}$ manual injection, DGU-14A degasser, SCL-10A $\mathrm{A}_{\mathrm{vp}}$ system controller and Class-VP chromatography data system; a reversed phase column Nucleosil $C_{8}$ endcapped $(150 \times 4.6 \mathrm{~mm}, 100 \AA$, $5 \mu \mathrm{m})$ from MachereyNagel (MN) and a guard column Phenomenex were used in the study.

The mobile phase contained a mixture of acetonitrile, water and triethylamine (70:30:0.085, $\mathrm{v} / \mathrm{v} / \mathrm{v})$, at a constant flow-rate of 1.2 $\mathrm{mL} \cdot \mathrm{min}^{-1}$ and at room temperature $\left(20 \pm 2^{\circ} \mathrm{C}\right)$. The $\mathrm{pH}$ value of the aqueous phase was adjusted to 7.5 with phosphoric acid. Aliquots of $20 \mu \mathrm{L}$ were injected. The detector was operated at a wavelength of $210 \mathrm{~nm}$.

Standard and sample preparation: The working standard solutions were obtained by dilution, in the mobile phase, of a 500 $\mu \mathrm{g} \cdot \mathrm{mL}^{-1}$ solution of milnacipran hydrochloride in methanol.

The average weight of the content of pharmaceutical dosage form ( $25 \mathrm{mg}$ of milnacipran hydrochloride) was calculated. An amount equivalent to $5 \mathrm{mg}$ of milnacipran hydrochloride was transferred into a $10 \mathrm{~mL}$ volumetric flask. An aliquot $(5 \mathrm{~mL})$ of methanol was added, sonicated for about $5 \mathrm{~min}$, diluted with the same solvent, mixed and filtered. An aliquot of the filtrate was diluted with mobile phase to yield a final concentration of $60 \mu \mathrm{g} \cdot \mathrm{mL}^{-1}$.

\section{Validation procedures - LC method}

Specificity: The interference from inactive ingredients was investigated by the analysis of a blank pharmaceutical formulation. Potential degradation products generated by forced decomposition (stress) of samples were also investigated for interference with the analytical method. The stress conditions used were: hydrolytic studies, oxidative, thermal and photodegradation. All solutions injected (sample and working standard solutions) were analyzed against a control solution stored at room temperature. Peak purity test (photodiode array detector) was useful to show that the chromatographic peak of the analyte did not contain impurities.

Hydrolytic studies: Methanolic solutions of milnacipran hydrochloride reference substance and capsules $\left(500 \mu \mathrm{g} \cdot \mathrm{mL}^{-1}\right)$ were exposed to $1 \mathrm{~N} \mathrm{HCl}$ and $1 \mathrm{~N} \mathrm{NaOH}(10: 1, \mathrm{v} / \mathrm{v})$, at room temperature for $5 \mathrm{~h}$. For neutral conditions, the solutions were diluted in water $(10: 3$, $\mathrm{v} / \mathrm{v}$ ) and heated at $60^{\circ} \mathrm{C}$ for $4 \mathrm{~h}$, using a water bath. The solutions were neutralized (when necessary) and diluted $\left(100 \mu \mathrm{g} \cdot \mathrm{mL}^{-1}\right)$ in mobile phase, before injection.

Oxidative effect: Solutions of milnacipran hydrochloride reference substance and capsules $\left(500 \mu \mathrm{g} \cdot \mathrm{mL}^{-1}\right)$ in methanol were both exposed to $3 \% \mathrm{H}_{2} \mathrm{O}_{2}$ at room temperature for $6 \mathrm{~h}$. The solutions were diluted $\left(100 \mu \mathrm{g} \cdot \mathrm{mL}^{-1}\right)$ in mobile phase before injection.

Thermal degradation: Solution of milnacipran hydrochloride reference substance $\left(500 \mu \mathrm{g} \cdot \mathrm{mL}^{-1}\right)$ in methanol was kept in an oven at $80^{\circ} \mathrm{C}$ for $24 \mathrm{~h}$. After this time, the solution was diluted $\left(50 \mu \mathrm{g} \cdot \mathrm{mL}^{-1}\right)$ in mobile phase before injection.

Photolysis test: Solutions of milnacipran hydrochloride reference substance and capsules $\left(500 \mu \mathrm{g} \cdot \mathrm{mL}^{-1}\right)$ in methanol were both exposed in a UV light chamber (352 nm) for about $20 \mathrm{~h}$. The drug was recovered and dissolved again with methanol and diluted $\left(100 \mu \mathrm{g} \cdot \mathrm{mL}^{-1}\right)$ in mobile phase before injection.

The conditions which presented some secondary peak were repeated for, at least, $24 \mathrm{~h}$ and diluted $\left(60 \mu \mathrm{g} \cdot \mathrm{mL}^{-1}\right)$ in mobile phase before injection.
Linearity: Milnacipran hydrochloride was accurately weighed $(10 \mathrm{mg})$ and dissolved in a $20 \mathrm{~mL}$ volumetric flask with methanol. This solution was diluted appropriately in mobile phase to yield solutions ranging from 20 to $100 \mu \mathrm{g} \cdot \mathrm{mL}^{-1}$. For the construction of each calibration curve, five different drug concentrations were analyzed in triplicate. Linearity of three calibration curves was tested by ANOVA and linear regression analysis.

Precision: Assay performance was evaluated by intraday and interday (three different days) precision, determined from replicate analysis of samples $\left(60 \mu \mathrm{g} \cdot \mathrm{mL}^{-1}\right)$ in three analytical runs. Analysis of six different sample solutions was performed in the same day for intraday precision. The precision was expressed in terms of relative standard deviations (RSD) from mean intra and interday assays.

Acuracy: Accuracy (recovery test) of the method was tested by adding a known amount of reference substance $\left(15,30,45 \mu \mathrm{g} \cdot \mathrm{mL}^{-1}\right)$ in three sample solutions $\left(30 \mu \mathrm{g} \cdot \mathrm{mL}^{-1}\right)$ to provide a final concentration of $45,60,75 \mu \mathrm{g} \cdot \mathrm{mL}^{-1}$, respectively. The accuracy was expressed in terms of recovery (\%) of the theoretical concentration of reference substance added.

Robustness: Robustness was tested by analysis of variations in analytical condition. Influence of $\mathrm{pH}$ values of the aqueous phase, flow rate and different columns were evaluated. The chromatographic parameters monitored were peak retention time, capacity factor, tailing factor and theoretical plate number.

\section{UV-D² spectroscopic conditions}

A double-beam UV-visible spectrophotometer (SHIMADZU, Japan) Model UV-1601 PC was used. The software employed was UVPC personal spectroscopy software, version 3.9. For all the tested solutions the second derivative spectra $\left(D^{2}\right)$ was recorded over the range $280-250 \mathrm{~nm}$ against solvent in a $1-\mathrm{cm}$ quartz cells, fixing $\Delta \lambda$ at $4 \mathrm{~nm}$ and scaling factor at 200 . The amplitude values of $D^{2}$ were measured at $268.5 \mathrm{~nm}$ for milnacipran hydrochloride, zero crossing of inactive ingredients.

Standard and sample solutions: Milnacipran hydrochloride reference substance was accurately weighted $(50 \mathrm{mg})$ and dissolved in a $100 \mathrm{~mL}$ volumetric flask with ethanol to generate a stock standard solution containing $500 \mu \mathrm{g} \cdot \mathrm{mL}^{-1}$ analyte. Working standard solutions were prepared by diluting the stock standard solution with $0.1 \mathrm{~N} \mathrm{HCl}$ to yield appropriate concentrations.

The average weight of the content of capsules $(25 \mathrm{mg})$ was calculated. An amount equivalent to $5 \mathrm{mg}$ of milnacipran hydrochloride was transferred into a $10 \mathrm{~mL}$ volumetric flask. An aliquot $(5 \mathrm{~mL})$ of ethanol was added, sonicated for about $5 \mathrm{~min}$, diluted with the same solvent, mixed and filtered. An aliquot of the filtrate was diluted with $0.1 \mathrm{~N} \mathrm{HCl}$ to yield a final concentration.

Validation Procedures - UV-D ${ }^{2}$ method: Preliminary tests were made to select the most convenient parameters (derivative order, analytical wavelength $(\lambda), \Delta \lambda$ and scaling factor).

Specificity: The specificity of the analytical method was evaluated with a solution of inactive ingredients (placebo). Their concentrations in pharmaceutical formulation were based in the literature (15) and calculated for the average weight of content $(110.0 \mathrm{mg})$ of the capsules.

Linearity: Linearity was tested by analyzing five different milnacipran hydrochloride concentrations in triplicate. Milnacipran hydrochloride reference substance was accurately weighed $(10 \mathrm{mg})$ 
Citation: Dias CL, Bajerski L, Rossi RC, Bergold AM, Fröehlich PE (2010) Comparative Validation Study to Assay Milnacipran Hydrochloride in Capsules by a Stability-Indicating LC and a Second Order Derivative UV Spectroscopic Methods. Pharm Anal Acta 1:112. doi:10.4172/21532435.1000112

Page 3 of 5

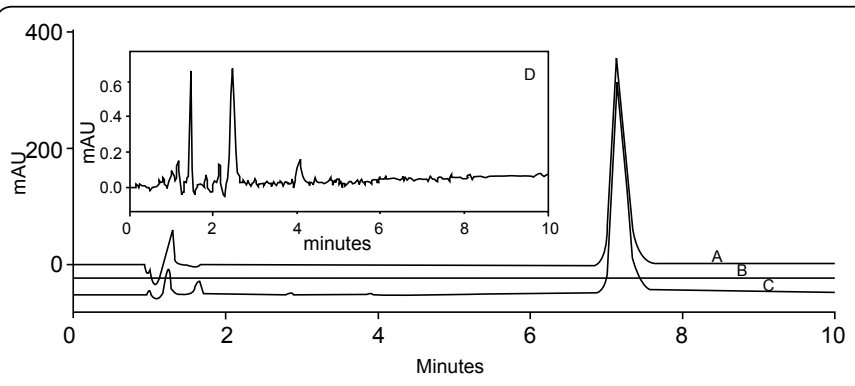

Figure 2: Chromatogram of milnacipran hydrochloride $\left(60 \mu \mathrm{g} \cdot \mathrm{mL}^{-1}\right)$ : (A) standard solution, (B) and (D) placebo and (C) sample solution.
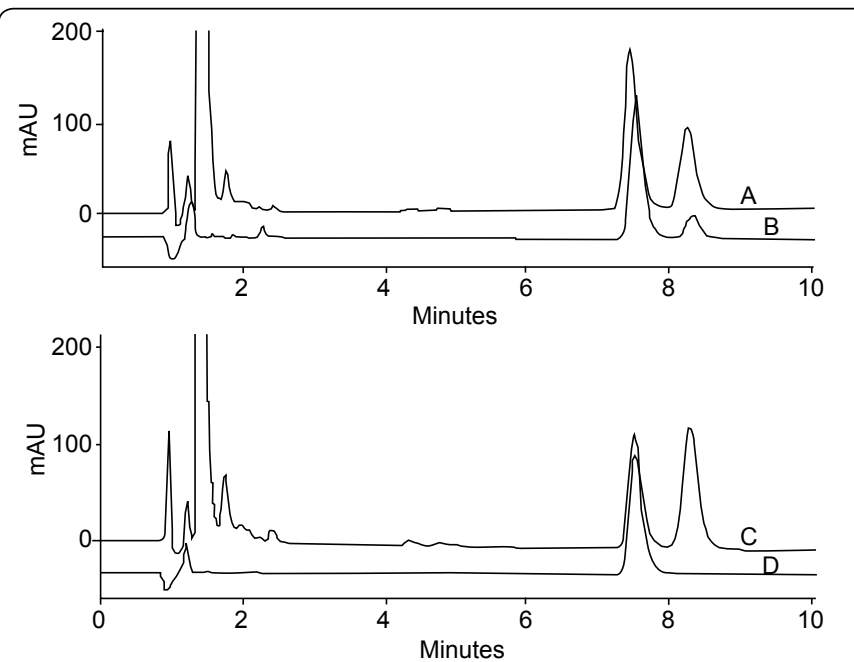

Figure 3: Specificity: chromatogram of potential degradation product. (A) oxidation test and (B) alkali hydrolysis for standard solution $\left(60 \mu \mathrm{g} \cdot \mathrm{mL}^{-1}\right)$ and $(\mathrm{C})$ oxidation test and (D) alkali hydrolysis for sample solution $\left(60 \mu \mathrm{g} \cdot \mathrm{mL}^{-1}\right)$.

and dissolved in a $20 \mathrm{~mL}$ volumetric flask with ethanol $\left(500 \mu \mathrm{g} \cdot \mathrm{mL}^{-1}\right)$. This solution was diluted in ethanol to produce solutions with appropriate concentrations $\left(100,200,300\right.$ and $\left.400 \mu \mathrm{g} \cdot \mathrm{mL}^{-1}\right)$ and, then, dilute them, respectively, in $0.1 \mathrm{~N} \mathrm{HCl}$ to yield final concentrations, covering the range of $20-100 \mu \mathrm{g} \cdot \mathrm{mL}^{-1}$. Linearity of three calibration curves was tested by ANOVA and linear regression analysis.

Precision: Assay performance was evaluated by repeatability and intermediate precision (three different days), determined from replicate analysis of samples at $60 \mu \mathrm{g} \cdot \mathrm{mL}^{-1}(\mathrm{n}=6)$. The precision was expressed in terms of relative standard deviations (RSD) from mean intra and inter-day assays.

Accuracy: Accuracy of the method was evaluated by adding a known amount of milnacipran hydrochloride reference substance $(15$, $\left.30,45 \mu \mathrm{g} \cdot \mathrm{mL}^{-1}\right)$ in three sample solutions $\left(30 \mu \mathrm{g} \cdot \mathrm{mL}^{-1}\right)$ to provide a final concentration of $45,60,75 \mu \mathrm{g} \cdot \mathrm{mL}^{-1}$, respectively. An adequate aliquot of ethanol was added in each volumetric flask to adjust the volume of solvent, before the final dilution with $0.1 \mathrm{~N} \mathrm{HCl}$. The accuracy was expressed in terms of recovery (\%) of the theoretical concentration of reference substance added.

\section{Results and Discussion}

\section{Selection of chromatographic conditions}

The best conditions were selected based on peak performance and the run time of the proposed assay was 10 min under isocratic elution. During injection of a standard solution the retention time was about 7.5 minutes for milnacipran hydrochloride (Figure 2A). The chromatogram of the placebo (Figure 2B and Figure 2D) showed no interference of inactive ingredients. The chromatogram obtained from a sample solution $\left(60 \mu \mathrm{g} \cdot \mathrm{mL}^{-1}\right)$ is shown in (Figure $2 \mathrm{C}$ ).

Different chromatographic columns were evaluated, but parameters for the analyte peak, as asymmetry and theoretical plates, were improved just by controlling temperature $\left(50^{\circ} \mathrm{C}\right)$, whereas the column used showed good performance at room temperature. Several mobile phases with different proportions of organic solvent (acetonitrile and methanol) were tested in order to achieve the best condition. A mixture of acetonitrile and water as mobile phase provided the best chromatographic performance. Considering its pka value of $10.36 \pm 0.29$ (16), a $\mathrm{pH}$ of 7.5 was used to ensure complete ionization of the analyte. The $\mathrm{pH}$ of aqueous phase with triethylamine was adjusted with phosphoric acid $20 \%(\mathrm{v} / \mathrm{v})$ before mixing with acetonitrile. Retention time and asymmetry were significantly affected by different amounts of triethylamine and the best results were achieved when using $0.085 \%$.

\section{LC method validation}

Specificity: Interference with the analytical method was evaluated with a solution of inactive ingredients (placebo solution). Their concentrations in pharmaceutical formulation were based on the literature [15] and calculated for an average weight of content $(\approx$ $110.0 \mathrm{mg}$ ) of the capsules. The chromatogram showed absence of any peak due to inactive ingredients (Figure 2B).

Interferences of potential degradation products were also investigated through forced decomposition tests. Sample solutions were exposed to thermal degradation, photolysis and oxidation test, acidic and alkaline conditions. The solutions subjected to stress (standard and sample solutions) and the control solutions which were stored under normal conditions were used to confront the quantitative results. The aliquots were neutralized (when necessary) and diluted before analysis. The chromatograms showed suitable separation from potential degradation products of milnacipran hydrochloride and photodiode array data was collected to evaluate peak purities.

A potential degradation product was observed in standard solutions exposed to 3\% hydrogen peroxide (Figure 3A) and $1 \mathrm{M}$ $\mathrm{NaOH}$ (Figure 3B). This degradation peak presented retention time of 8.3 minutes and resolution of 2.2. However, the sample solutions (capsules) showed this secondary peak only with oxidative stress (Figure 3C), whereas under alkaline hydrolysis it was not observed (Figure 3D). The chromatogram of the oxidation test showed some extra peaks from hydrogen peroxide. Under acid and neutral hydrolysis, thermal and photolytic degradation no additional peak was detected.

The most important effect of degradation studies (above 10\% of degradation) occurred by effect of oxidation and alkaline hydrolysis. The results suggest that the degradation product observed is the same in both conditions, according to both UV spectra and retention times. Interaction with inactive ingredients could explain the reason why the analyte was more stable than bulk substance under alkaline hydrolysis.

Photodiode array purity test showed no impurity in the milnacipran hydrochloride peak after degradation and the assay was considered selective. 
Citation: Dias CL, Bajerski L, Rossi RC, Bergold AM, Fröehlich PE (2010) Comparative Validation Study to Assay Milnacipran Hydrochloride in Capsules by a Stability-Indicating LC and a Second Order Derivative UV Spectroscopic Methods. Pharm Anal Acta 1:112. doi:10.4172/21532435.1000112

Page 4 of 5

\begin{tabular}{|l|l|l|l|l|}
\hline \multirow{2}{*}{ Intraday $(n=6)$} & Mean observed value $(\%) \pm$ SE & \multicolumn{2}{l|}{ RSD (\%) } \\
\cline { 2 - 5 } & LC & UV-D & LC & UV-D \\
\hline day I & $101.39 \pm 0.42$ & $100.55 \pm 0.18$ & 1.01 \\
\hline day II & $100.79 \pm 0.18$ & $101.20 \pm 0.39$ & 0.45 \\
\hline day III & $101.88 \pm 0.25$ & $101.01 \pm 0.16$ & 0.59 & \\
\hline Interday $(n=3)$ & $101.35 \pm 0.32$ & $100.92 \pm 0.19$ & 0.94 & 0.54 \\
\hline
\end{tabular}

Table 1: Repeatability and intermediate precision to assay milnacipran capsules.

\begin{tabular}{|c|c|c|c|c|c|c|c|c|}
\hline \multirow{3}{*}{ Sample solution $\left(\mu \mathrm{g} \cdot \mathrm{mL}^{-1}\right)$} & \multirow{3}{*}{ Standard solution $\left(\mu \mathrm{g} \cdot \mathrm{mL}^{-1}\right)$} & \multirow{3}{*}{ Total concentration $\left(\mu \mathrm{g} \cdot \mathrm{mL}^{-1}\right)$} & \multicolumn{6}{|c|}{ Recovery \% } \\
\hline & & & \multicolumn{2}{|c|}{ I } & \multicolumn{2}{|l|}{ II } & \multicolumn{2}{|l|}{ III } \\
\hline & & & LC & UV-D'2 & LC & UV-D ${ }^{2}$ & LC & UV-D ${ }^{2}$ \\
\hline 30 & 15 & 45 & 101.2 & 98.5 & 100.3 & 100.2 & \begin{tabular}{|l|}
101.4 \\
\end{tabular} & 100.5 \\
\hline 30 & 30 & 60 & 99.1 & 98.7 & 98.5 & 100.0 & 99.7 & 101.4 \\
\hline 30 & 45 & 75 & 99.2 & 99.6 & 98.6 & 101.6 & 99.2 & 101.0 \\
\hline \multicolumn{3}{|c|}{ Mean absolute recovery $(\%) \pm \operatorname{SE}(n=9)$} & \multicolumn{3}{|c|}{ LC } & \multicolumn{3}{|l|}{ UV-D ${ }^{2}$} \\
\hline
\end{tabular}

Table 2: Accuracy of the analysis of milnacipran in capsules

\begin{tabular}{|c|c|c|c|c|c|}
\hline & Retention time (min) & Theoretical plates $(N>2000)^{b}$ & Tailing factor $(T \leq 2)^{\mathrm{b}}$ & Capacity factor $\left(k^{\prime}>2\right)^{b}$ & Assay (\%) \\
\hline Method proposed ${ }^{a}$ & 7.6 & 8367 & 1.4 & 5.3 & 100.8 \\
\hline Mobile phase: $\mathrm{pH} 7.0$ & 7.2 & 8369 & 1.4 & 5.0 & 99.2 \\
\hline Mobile phase: $\mathrm{pH} 8.0$ & 8.1 & 8088 & 1.4 & 5.8 & 99.1 \\
\hline flow rate: $1.0 \mathrm{~mL} \cdot \mathrm{min}^{-1}$ & 8.8 & 8937 & 1.4 & 8.6 & 100.7 \\
\hline Analytical Column Merck C8 $(125 \times 4.6 \mathrm{~mm}) * 1.0 \mathrm{~mL} \cdot \mathrm{min}^{-1}$ & 3.7 & 2702 & 2.0 & 2.1 & 100.6 \\
\hline
\end{tabular}

Table 3: Evaluation of robustness for the milnacipran capsules LC assay.

Linearity: Calibration curves proved to be linear over the $20-100 \mu \mathrm{g} \cdot \mathrm{mL}^{-1}$ range. Standard solutions prepared at five concentrations $\left(20,40,60,80\right.$ and $\left.100 \mu \mathrm{g} \cdot \mathrm{mL}^{-1}\right)$ were injected in triplicate every day, during three consecutive days. Linear regression of concentration versus peak area ratio plots resulted in an average coefficient of determination $\left(\mathrm{R}^{2}\right)$ greater than 0.999 . The average equation for three calibration curves was $y=0.0109+0.465 x$. The data was evaluated by ANOVA. It presented linear regression $\left(\mathrm{F}_{\text {calculated }}\right.$ $\left.=162715.76>\mathrm{F}_{\text {critical }}=4.96 ; \mathrm{P}=0.05\right)$ and it did not deviate from linearity $\left(\mathrm{F}_{\text {calculated }} \stackrel{\text { crtical }}{=} 2.97<\mathrm{F}_{\text {critical }}=3.71 ; \mathrm{P}=0.05\right)$.

Precision: The intraday and interday precision were estimated from the triplicate injections of six sample solutions prepared at $60 \mu \mathrm{g} \cdot \mathrm{mL}^{-1}$ of milnacipran hydrochloride (test concentration) analyzed in three separate days. Means and relative standard deviations (RSD) were obtained from calculated milnacipran hydrochloride concentrations (Table 1). The variability was low with RSD values ranging from $0.4 \%$ to $1.0 \%$. These results indicated that the assay is reproducible.

Accuracy: Accuracy was calculated as the percentage of recovery by the assay of known added amounts of milnacipran hydrochloride reference substance in sample solutions using three concentration levels covering the specified range and three replicates of each concentration. The accuracy of the method ranged from 98.5 to $101.4 \%$, indicating that the assay is accurate (Table 2).

Robustness: The chromatographic analysis under different analytical conditions was performed and the chromatographic parameters of the main peak were evaluated presenting only few changes. A different brand of analytical column (Merck) was tested, increasing tailing factor and considerably reducing retention time and theoretical plate number. Changes in $\mathrm{pH}$ and flow rate were evaluated in robustness and they did not interfere with the analytical parameters. The results of robustness are presented in (Table 3).

Stability of Standard and Sample Preparation: Stock solutions of milnacipran hydrochloride reference substance and capsules $\left(500 \mu \mathrm{g} \cdot \mathrm{mL}^{-1}\right)$ in methanol were stable for $24 \mathrm{~h}$ at room temperature and at $4^{\circ} \mathrm{C}$. There was no evidence of degradation of the analyte under these conditions.

\section{UV-D ${ }^{2}$ method validation}

Specificity: Solutions of standard, sample and inactive ingredients were evaluated over the range 300-200 nm in the zero (Figure 4-a), first and second UV-derivative orders. Background interferences and overlaps from pharmaceutical formulation were eliminated by selecting the best parameters of the UV-D method for the quantitative determination of milnacipran hydrochloride in capsules.

Results showed that UV-D ${ }^{2}$ measurement of milnacipran hydrochloride is possible at $268.5 \mathrm{~nm}$ because at this wavelength the influence from excipients was not observed (Figure 4-b).

Linearity: The results showed that the UV-D² absorbance was proportional to milnacipran hydrochloride concentration (Figure 5). Standard solutions prepared at five concentrations $(20,40,60,80$ and $100 \mu \mathrm{g} \cdot \mathrm{mL}^{-1}$ ) were measured in triplicate every day, during three consecutive days. The average equation for three calibration curves was $y=0.0023+0.0027 x$ and the average correlation coefficient (r) obtained was 0.9999 . The linearity data were evaluated using ANOVA, this showed that the regression equation was linear $\left(\mathrm{F}_{\text {calculated }}\right.$ $=1960.55>\mathrm{F}_{\text {critical }}=4.96 ; \mathrm{P}=0.05$ ) with no deviation from linearity $\left(\mathrm{F}_{\text {calculated }}=0.0453<\mathrm{F}_{\text {critical }}=3.71 ; \mathrm{P}=0.05\right)$.

Precision: The repeatability and intermediate precision were estimated from the triplicate measurements of six different sample solutions at $60 \mu \mathrm{g} \cdot \mathrm{mL}^{-1}$ of milnacipran hydrochloride and analyzed for three different days. The results indicated that UV- ${ }^{2}$ assay is reproducible. The RSD were obtained from calculated milnacipran hydrochloride concentrations in capsules over all days, mean intra and inter-day assays. The variability was low with RSD values ranging from $0.07 \%$ to $1.00 \%$ (Table 1 ).

Accuracy: Accuracy was calculated as the percentage recovery of known added amounts of milnacipran hydrochloride reference substance in the sample solutions using three concentration levels covering the specified range and three replicates of each concentration. The mean accuracy of the method ranged from $98.5 \%$ to $101.6 \%$ indicating that this assay is reliable (Table 2).

\section{Statistical comparison of LC and UV-D ${ }^{2}$ methods}

The $t$-test was used ( $t$ Table value 2.03 for 34 degrees of freedom) to compare the UV-D ${ }^{2}$ spectroscopic with the LC method. The assay data obtained from the two methods showed non-significant difference at the confidence level of $95 \%(P=0.05)$ with the statistic $t$ (1.73) being smaller than the critical value. 
Citation: Dias CL, Bajerski L, Rossi RC, Bergold AM, Fröehlich PE (2010) Comparative Validation Study to Assay Milnacipran Hydrochloride in Capsules by a Stability-Indicating LC and a Second Order Derivative UV Spectroscopic Methods. Pharm Anal Acta 1:112. doi:10.4172/21532435.1000112

Page 5 of 5
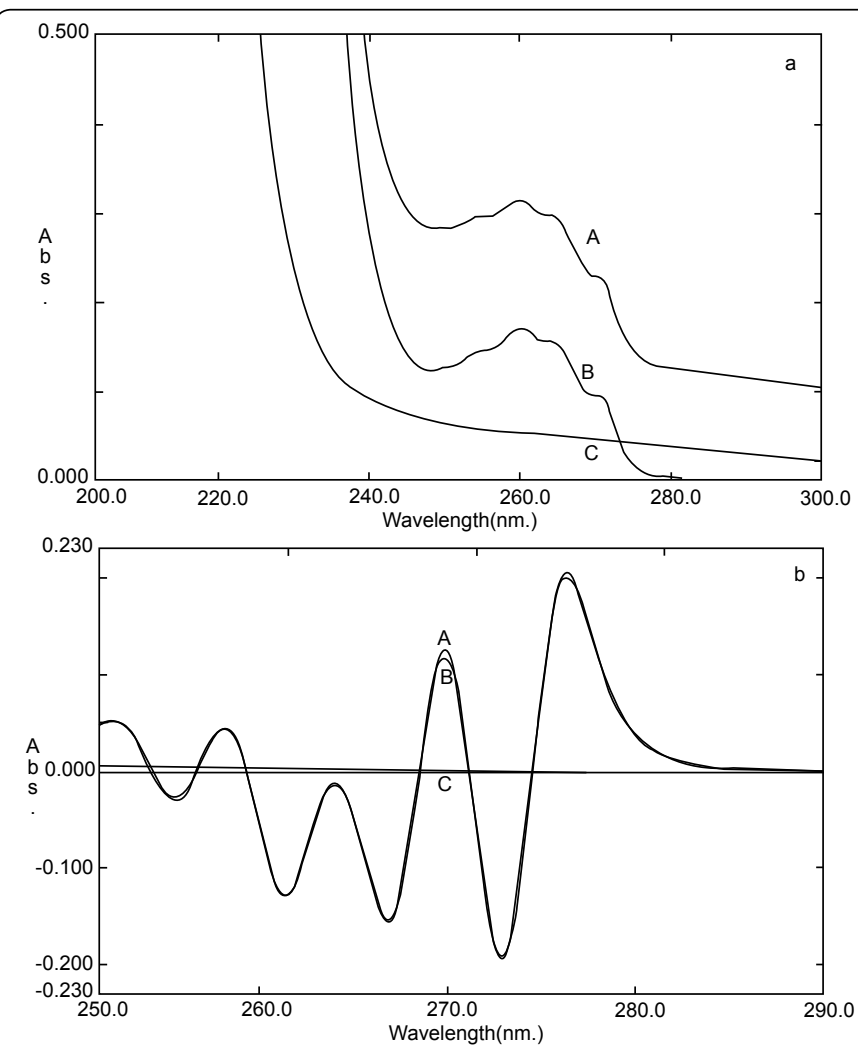

Figure 4a: UV-zero order $\left(D^{\circ}\right)$ spectra of $(A)$ sample solution $\left(60 \mu \mathrm{g} \cdot \mathrm{mL}^{-1}\right)$ (B) milnacipran hydrochloride standard solution $\left(60 \mu \mathrm{g} \cdot \mathrm{mL}^{-1}\right)$ and $(C)$ placebo solution in $0.1 \mathrm{~N} \mathrm{HCl}$. b: UV-second order $\left(\mathrm{D}^{2}\right)$ spectra, respectively.

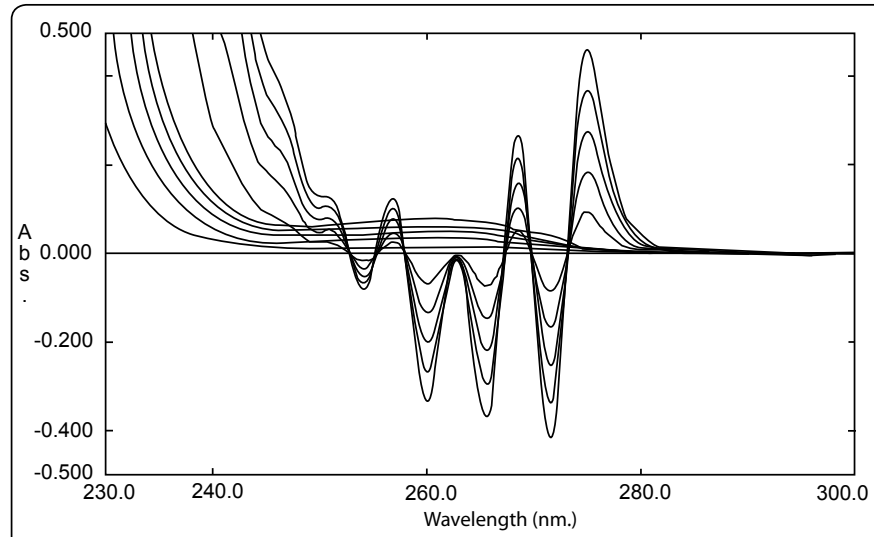

Figure 5: Overlay of UV-D ${ }^{\circ}$ spectra and UV-D² spectra for milnacipran hydrochloride standard solutions $\left(20-100 \mu \mathrm{g} \cdot \mathrm{mL}^{-1}\right)$ in $0.1 \mathrm{~N} \mathrm{HCl}$.

\section{Conclusion}

The absence of official methods to quantify milnacipran hydrochloride justifies the need of analytical procedures for assuring the quality of its pharmaceutical dosage form. The LC method developed and validated allows a simple and fast quantitative determination of milnacipran hydrochloride in capsules, ensuring that it is suitable for determining the content of milnacipran hydrochloride in this dosage form despite the presence of its major degradation products. The proposed UV- $\mathrm{D}^{2}$ spectroscopic method presents itself as an alternative to the LC method, since the statistical analysis by Student's $t$ test suggests that the two methods are equivalent for the quantitative determination of drug in capsules. Besides, the UV-D method is an analytical technique of great utility, when compared with conventional UV-visible spectroscopic method, offering selectivity against the interference of the excipients, without preliminary separation.

\section{Acknowledgments}

This research was supported by the Medicinal Chemistry Laboratory (UFRGS) The authors would like to thank CNPQ (Brazil), for the financial support.

\section{References}

1. Chen C, Dyck B, Fleck BA, Foster AC, Grey, et al. (2008) Identification of 1S, 2R-milnacipran analogs as potent norepinephrine and serotonin transporter inhibitors. Bioorganic \& Medicinal Chemistry 18: 3328-3332.

2. NLM ChemIDplus Advanced (2009) http://chem.sis.nlm.nih.gov/chemidplus/ chemidheavy.jsp

3. Vaishnavi SN, Nemeroff CB, Plott SJ, Rao SG, Kranzler J, et al. (2004) Milnacipran: a comparative analysis of human monoamine uptake and transporter binding affinity. Biological Psychiatry 55: 320-322.

4. Rao SG, Gendreau JF, Kranzler JD (2008) Understanding the Fibromyalgia Syndrome. Psychopharmacology Bulletin 40: 24-56.

5. Lacassie E, Gaulier JM, Marquet P, Rabatel JF, Lachâtre G (2000) Methods for the determination of seven selective serotonin reuptake inhibitors and three active metabolites in human serum using high-performance liquid chromatography and gas chromatography. Journal of Chromatography B 742: 229-238.

6. Tournel G, Houdret N, Hédouin V, Deveaux M, Gosset D, et al. (2001) High-performance liquid chromatographic method to screen and quantitate seven selective serotonin reuptake inhibitors in human serum. Journal of Chromatography B 761:147-158.

7. Duverneuil C, Grandmaison GL, Mazancourt P, Alvarez JC (2003) A HighPerformance Liquid Chromatography Method with Photodiode-Array UV Detection for Therapeutic Drug Monitoring of the Nontricyclic Antidepressant Drugs. Therapeutic Drug Monitoring 25: 565-573.

8. Puozzo C, Filaquier C, Zorza G (2004) Determination of milnacipran, serotonin and noradrenaline reuptake inhibitor, in human plasma using liquid chromatography with spectrofluorimetric detection. Journal of Chromatography B 806: 221-228.

9. Shinozuka T, Terada M, Tanaka E (2006) Solid- phase extraction and analysis of 20 antidepressant drugs in human plasma by LC/MS with SSI method. Forensic Science International 162: 108-112.

10. Labat L, Deveaux M, Dallet P, Dubost JP (2002) Separation of new antidepressants and their metabolites by micellar electrokinetic capillary chromatography. Journal of Chromatography B 773: 17-23.

11. Patti A, Pedotti S, Sanfilippo C (2007) Chirality 20: 63-68.

12. Reviewer Guidance: Validation of Chromatographic Methods (1994) FDA CDER, Rockville, MD.

13. ICH (2003) Stability Testing of New Drug Substances and Products $Q 1 A(R 2)$ In: International Conference on Harmonization of Technical Requirements for Registration of Pharmaceuticals for Human Use.

14. ICH (2005) Validation of Analytical Procedures: Text And Methodology, Q2(R1). In: International Conference on Harmonization of Technical Requirements for Registration of Pharmaceuticals for Human Use.

15. Kibbe AH, Wade A, Weller PJ (eds) (2000) Handbook of Pharmaceutica Excipients. ( $3^{\text {rd }}$ ed), Pharmaceutical Press, London.

16. ACD/Labs Online, version 8.0. (2009) http://ilab.acdlabs.com 